\title{
Factors Affecting the Survival of Bremia lactucae Sporangia Deposited on Lettuce Leaves
}

\author{
B. M. Wu, K. V. Subbarao, and A. H. C. van Bruggen
}

Department of Plant Pathology, University of California, Davis 95616.

Current address of B. M. Wu: Department of Plant Pathology, University of California, Davis, U.S. Agricultural Research Station, 1636 East Alisal Street, Salinas 93905.

Current address of A. H. C. van Bruggen: Biological Farming Systems, Wageningen University and Research Center, Marijikeweg 22, 6709

PG Wageningen, the Netherlands.

Accepted for publication 10 April 2000.

\begin{abstract}
Wu, B. M., Subbarao, K. V., and van Bruggen, A. H. C. 2000. Factors affecting the survival of Bremia lactucae sporangia deposited on lettuce leaves. Phytopathology 90:827-833.

Experiments to identify the factors affecting survival of Bremia lactucae sporangia after deposition on lettuce leaves were conducted in growth chambers and outdoors under ambient conditions. Lettuce seedlings at the four-leaf stage were inoculated with B. lactucae sporangia under dry conditions. Sporangia deposited on lettuce seedlings were incubated at different temperature and relative humidity ( $\mathrm{RH})$ combinations, exposed to $100,50,25$, and $0 \%$ sunlight in the second experiment, and exposed to different artificial lights in wavelength ranges of UVA (315 to $400 \mathrm{~nm}$ ), UVB (280 to $315 \mathrm{~nm}$ ), or fluorescent light in the third experiment. After exposure for 0 to $48 \mathrm{~h}$ in the first experiment and 0 to $12 \mathrm{~h}$ in the second and third experiments, seedlings in two pots were

mined in water after incubation in the dark at $15^{\circ} \mathrm{C}$ for $24 \mathrm{~h}$. The sampled seedlings with remaining leaves were first transferred to optimal conditions for infection $(24 \mathrm{~h})$, for the development of downy mildew, and then assessed for disease after 9 days. Sporangia survived much longer at $23^{\circ} \mathrm{C}(>12 \mathrm{~h})$ than at $31^{\circ} \mathrm{C}(2$ to $5 \mathrm{~h})$, regardless of $\mathrm{RH}$ (33 to $76 \%$ ). Germination percentage was significantly reduced after exposure to 50 and $100 \%$ sunlight. UVB significantly reduced sporangium viability, while fluorescent light and UVA had no effect relative to incubation in the dark. Infection of seedlings followed a pattern similar to germination of sporangia. Solar radiation is the dominant factor determining survival of $B$. lactucae sporangia, while temperature and $\mathrm{RH}$ have small, insignificant effects in coastal areas of California. This suggests that infections by sporangia that survived a day are probable only on cloudy days or on leaves that are highly shaded.
\end{abstract} sampled for each treatment, and sporangia were washed from 15 leaves excised from the sampled seedlings. Germination of sporangia was deter-

Downy mildew (caused by Bremia lactucae Regel) is a destructive disease of lettuce (Lactuca sativa L.) in both commercial fields and glasshouse production systems worldwide. The disease is controlled mainly by genetic resistance and application of fungicides. To maximize the effectiveness of fungicide applications and minimize the number of applications, it is necessary to predict infection and time fungicide application before infection.

Although B. lactucae produces oospores, secondary spread of the disease in the field exclusively results from infections by airborne sporangia. Sporulation of $B$. lactucae occurs nocturnally 5 to 14 days postinfection and is greatly inhibited by continuous light (30). Sporangium release in oomycetes is triggered by light $(19,28)$ and coincides with decreasing humidity, rising temperature, and evaporation of leaf wetness $(19,29)$. The release of $B$. lactucae sporangia starts at sunrise and reaches peak density between 1000 and $1200 \mathrm{~h}(11,27)$. Sporangia deposited soon after sunrise can infect the leaves if leaf wetness persists for another $3 \mathrm{~h}$ $(20,25,30)$. Because infection of lettuce by $B$. lactucae occurs mainly on days with prolonged duration of morning leaf wetness (26), it is assumed that sporangium release, germination, and infection take place the same morning and that prolonged morning leaf wetness is the requirement for infection of lettuce by $B$. lactucae (24). Based on these assumptions, an infection prediction model was developed and validated in coastal California (24).

Corresponding author: B. M. Wu; E-mail address: bmwu@ucdavis.edu

Publication no. P-2000-0516-01R

(C) 2000 The American Phytopathological Society
Additional keywords: lettuce downy mildew, ultraviolet radiation.
However, for sporangia released during late morning or when morning leaf wetness is shorter than $3 \mathrm{~h}$, the ability of sporangia to survive a dry day is critical for infection of lettuce during the following night. The omission of sporangium survival from the model may be one source of inaccuracy in the previous infection prediction model (24). The conditions under which sporangia released in the morning can survive a day and infect lettuce during the next night, i.e., the factors affecting the survival of released and deposited $B$. lactucae sporangia, have not been determined.

However, factors affecting sporangium survival for pathogens closely related to B. lactucae, e.g., Phytophthora infestans, Peronospora destructor, and Peronospora tabacina, have been investigated intensively. Temperature and relative humidity (RH) including moisture, have previously received the most attention among different environmental factors. Sporangia of $P$. infestans were believed to survive only a short time at low RH according to the early work of Crosier (7). However, De Weille (9) demonstrated that germination of $P$. infestans sporangia decreases very little after exposure to $31 \% \mathrm{RH}$ for as long as $10 \mathrm{~h}$. Viability of $P$. infestans sporangia declines slower at high humidity than at low humidity and slower at low temperatures than at high temperatures (21). Furthermore, $P$. infestans sporangia remain viable for a longer period on leaf surfaces than in the atmosphere even when the ambient air is dry (21). Minogue and Fry (17) determined that the germination ability of partially desiccated sporangia depends on the rate of subsequent rewetting, and a low rewetting rate favors survival. Peronospora tabacina, the causal agent of tobacco blue mold, is transmitted by wind over hundreds of kilometers (2). To remain viable during such long distance transport, sporangia 
must survive in the atmosphere for at least $12 \mathrm{~h}$. In laboratory studies, sporangia of Peronospora destructor have survived for 1 to 3 days or longer under cool temperatures and moderate RH but survived for shorter periods under high temperatures and high RH (3). Sporangia of Peronospora destructor usually die at night due to alternating wet and dry conditions, a phenomenon associated with slow dew formation, although they survive well during the day under a wide range of weather conditions (14).

Solar radiation (SR) is another important factor affecting the viability of sporangia in addition to temperature and RH. SR is the main cause of death of dispersed $P$. infestans sporangia $(4,9,22)$. Approximately $95 \%$ of sporangia of $P$. infestans are inactivated after exposure for $1 \mathrm{~h}$ on sunny days (18). Bashi and Aylor (3) also observed that SR is the dominant factor affecting survival of Peronospora destructor and Peronospora tabacina in the field, even more than temperature or RH. Sporangia of Peronospora destructor and Peronospora tabacina exposed to weak SR (7 to $280 \mathrm{~W} \mathrm{~m}^{-2}$ ) survive much longer than those exposed to moderate ( 280 to $630 \mathrm{~W} \mathrm{~m}^{-2}$ ) or strong $\left(630\right.$ to $900 \mathrm{~W} \mathrm{~m}^{-2}$ ) SR. Intense and moderately intense SR result in a rapid decline in viability of detached sporangia of Peronospora destructor and Peronospora tabacina. In contrast, sporangia of both species survive many hours under weak SR.

The UV component is the primary component of SR affecting the viability of sporangia. Nearly $99.5 \%$ of SR is in the 120 to $1,000 \mathrm{~nm}$ wavelength range, and less than $9 \%$ of all energy is UV radiation, which has three components: UVA (320 to $400 \mathrm{~nm}$ ), UVB (290 to $320 \mathrm{~nm})$, and UVC (<290 nm). Short UV (UVC) is 103 times more effective in killing sporangia of Peronospora tabacina than longer UV (UVA and UVB) (23), but UVC is practically absent in SR reaching the earth's surface. Although UVA is present in sunlight, it has a much smaller deleterious effect on biological organisms. Most of the deleterious effects of SR on biological organisms are due to UVB $(6,8,10)$. For example, UVB affects the viability of fungal spores such as Magnaporthe grisea (16), Venturia inaequalis (1), Exobasidium vexans (12), and Uncinula necator (32). The effects of UVB depend on the amount of atmospheric ozone, the angle of the sun in the sky, and the cloud cover that shields the surface of the earth from some of the

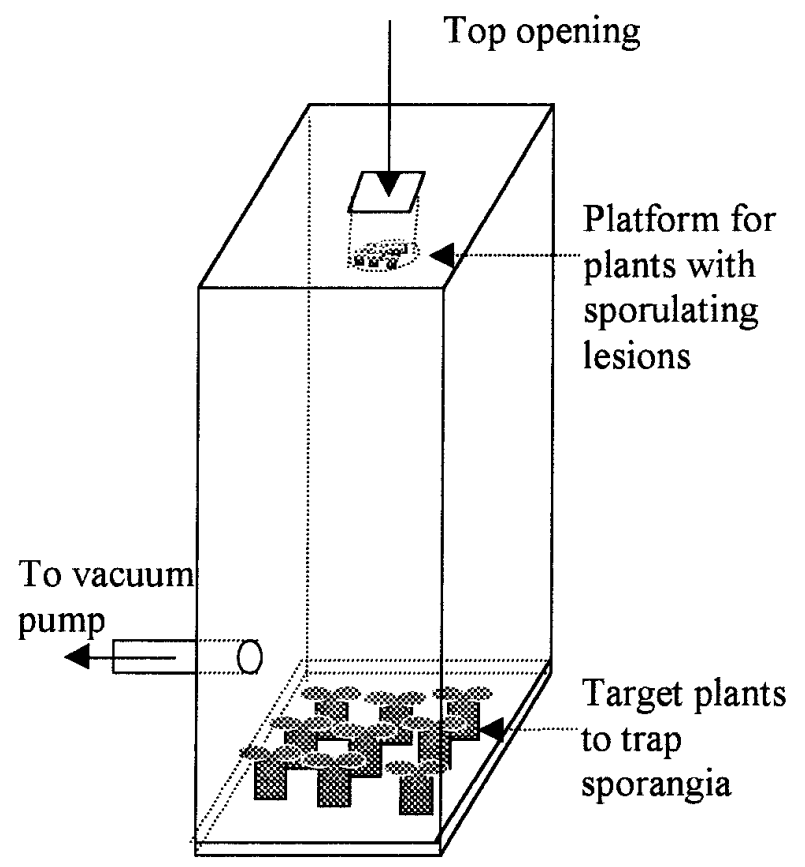

Fig. 1. Wooden inoculation tower used for inoculation of lettuce plants. Bremia lactucae sporangia were released from source plants by creating vacuum and letting in air. Released sporangia were deposited on target plants.
UV radiation. As stratospheric ozone diminishes, proportionately more of the UV radiation reaching the earth's surface will arrive in the UVB wavelength. By affecting the UVB component of SR, the reduction of stratospheric ozone will also play an important role in affecting the epidemics of downy mildew and other similar diseases. Research on the effects of UVB not only will help predict the survival of the pathogens under different weather conditions, but also provide clues to predict the long-term trends in plant diseases.

The objectives of this study were to determine the effects of temperature, $\mathrm{RH}$, and $\mathrm{SR}$ on the survival of B. lactucae sporangia and to identify the main wavelength range of SR affecting the survival of B. lactucae sporangia.

\section{MATERIALS AND METHODS}

Inoculum source and sporangium trap plants. Lettuce seeds of susceptible cv. Cobham Green were sterilized for $15 \mathrm{~min}$ in $0.5 \% \mathrm{NaOCl}$ and rinsed in sterile distilled water three times. The seeds were planted in polycarbonate tissue culture Magenta boxes on two layers of blotter paper moistened with $6 \mathrm{ml}$ of sterile halfstrength Hoagland's solution (15). The boxes were incubated at 25 to $30^{\circ} \mathrm{C}$ for germination, then moved to a growth chamber with light at $15^{\circ} \mathrm{C}$. When seedlings had well-extended cotyledons $(\approx 7$ days after planting), they were inoculated with a pathotype $\mathrm{V}$ isolate of B. lactucae (C960425-B, provided by O. Ochoa, University of California, Davis). The boxes were closed and incubated at $15^{\circ} \mathrm{C}$ for 6 days before the lids were opened to subject seedlings to ambient low $\mathrm{RH}$ in a growth chamber to prevent sporulation of B. lactucae. At this time, small volumes of sterile water were added to the boxes to prevent seedlings from desiccation. The next evening, the lids were closed again to increase humidity and provide optimal conditions for sporulation of $B$. lactucae. Approximately $12 \mathrm{~h}$ later, sporulating seedlings were used as an inoculum source for inoculation of target plants.

Lettuce seeds of cv. Alpha were planted in pots filled with UC soil mix and grown in growth chambers at 10 and $15^{\circ} \mathrm{C}$, respectively, on a $12 \mathrm{~h}$ night and $12 \mathrm{~h}$ day (cool white light at 0.2 to $4 \mathrm{~W} \mathrm{~m}^{-2}$ ) cycle. After the seedlings developed true leaves, they were thinned to retain equal numbers of seedlings of uniform growth stage in all pots ( 5 plants in each pot for temperature and $\mathrm{RH}$ experiments, and 10 plants in each pot for sunlight and UV experiments). At the third- or fourth-leaf stages, these seedlings were used to trap sporangia in the experiments described below.

Inoculation. The trap plants were horizontally positioned and evenly spaced at the bottom of an inoculation tower $(1.20 \mathrm{~m}$ high $\times$ $0.45 \mathrm{~m}$ long $\times 0.45 \mathrm{~m}$ wide; Fig. 1). Source plants with sporulating lesions were placed on a 9-cm petri dish fixed in the upper part of the tower. After subjecting the tower to vacuum for $10 \mathrm{~s}$, the top lid was opened to let in a puff of air to liberate sporangia. This procedure was repeated three times for each petri dish at 3-min intervals between every two vacuums to allow released sporangia to deposit on leaf surfaces of trap plants. The density of sporangia deposited on leaves during inoculation was determined by counting the sporangia deposited on three glass slides placed among trap plants.

Survival of sporangia after deposition. A split-plot design was used in experiments involving exposure of sporangia deposited on lettuce leaves to different combinations of temperature and RH. Two temperatures $\left(23\right.$ and $\left.31^{\circ} \mathrm{C}\right)$ were the main treatments, and four RH levels $(33,47,64$, and $76 \%$ ) were split within temperatures. In addition, both positive control (CK, inoculated) and negative control (noninoculated) treatments were included. Each control consisted of 4 pots of plants, while the other treatments consisted of 12 pots of trap plants each. Each RH was maintained within a plastic box $\left(31 \times 23 \times 10.5 \mathrm{~cm}^{3}\right)$ by adjusting the inflow speed of dry and moist air according to monitored RH values. Dry and moist air were generated by passing air through drierite gas drying jars and a flask of warm distilled water, respectively. Air 
temperature and RH levels in the boxes were monitored with temperature and RH probes (Model 207, Campbell Scientific Inc., Logan, UT) connected to a data logger (Model 21X, Campbell). The four plastic boxes with different RH levels were kept in the same growth chamber (described above, with a light intensity of 0.2 to $0.4 \mathrm{~W} \mathrm{~m}^{-2}$ ) at the same temperature. After exposure for 2, 5, $8,12,24$, and $48 \mathrm{~h}$, two pots of seedlings were sampled. The two temperature treatments in each experiment were separated in time, and the entire experiment was repeated three times.

To determine the effects of SR on survival of B. lactucae, plants with sporangia deposited on their leaves were exposed to different levels of SR. A randomized complete-block design with six replications was used. Four SR levels of 100\%, $50 \pm 6 \%, 25 \pm 3 \%$, and $0 \%$ of total natural SR were obtained by shading boxes with different materials (cheesecloth or paperboard) to filter natural sunlight. The experiments were done in an open space in Salinas during summer 1997. After exposure for $0,2,4,6,8$, and $10 \mathrm{~h}$ (in two of the experiments the 10-h sample was not collected), two pots of seedlings were sampled. Air temperature and $\mathrm{RH}$ were monitored in all experiments with temperature- $\mathrm{RH}$ probes connected to a $21 \mathrm{X}$ data logger. Total SR ( $\mathrm{W} \mathrm{m}^{-2}$ ), and total UV (290 to $385 \mathrm{~nm}$ ) (TUV in $\mathrm{W} \mathrm{m}^{-2}$ ) were measured with a total radiometer (pyranometer, Li-COR Inc., Lincoln, NE) and an UV radiometer (TUVR, Eppley Laboratory Inc., Newport, RI), respectively. Total SR was measured for all four treatments, but UV was measured only for the $100 \%$ SR treatment. The total UV for the other three treatments was estimated based on the ratios of SR in the corresponding treatment to that in the $100 \%$ treatment, because in a preliminary experiment the proportion of SR reduced by cheesecloth shading approximated the proportion of UV reduction by the cheesecloth.

To determine the wavelength range of sunlight that has an important effect on survival of sporangia, we also conducted exposure experiments under laboratory conditions. Inoculated trap plants were subjected to different artificial light sources instead of sunlight. Treatments were arranged in a randomized complete-block design, and the experiment was repeated three times. Six treatments, UVA1 $\left(6.0 \mathrm{~W} \mathrm{~m}^{-2}\right)$, UVA2 $\left(12.5 \mathrm{~W} \mathrm{~m}^{-2}\right)$, UVB1 $\left(1.5 \mathrm{~W} \mathrm{~m}^{-2}\right)$, UVB2 $\left(7.0 \mathrm{~W} \mathrm{~m}^{-2}\right)$, fluorescent (cool white) light $\left(4.0 \mathrm{~W} \mathrm{~m}^{-2}\right.$, Model F20T12/CW, General Electric, Cleveland), and darkness, were carried out in growth chambers at $15^{\circ} \mathrm{C}$ and $\mathrm{RH}$ at $\approx 50 \%$. UVA1 and UVA2 were obtained with one and three black light lamps (Model F20T12/350BL, Osram Sylvania Inc., Danvers, MA), respectively, with a wavelength range of 300 to $400 \mathrm{~nm}$ and a peak at 340 to $350 \mathrm{~nm}$. UVB1 and UVB2 were obtained with one and three UVB lamps (Model TL20W/12/RS, Philips Lighting, Eindhoven, the Netherlands), respectively, with a wavelength range of 280 to $315 \mathrm{~nm}$ and a peak at 305 to $310 \mathrm{~nm}$. After exposure for $0,2,4,8$, and $12 \mathrm{~h}$, two pots of seedlings were sampled.

Viability of sporangia after exposure. From the 2 pots of seedlings sampled, 15 (temperature-RH experiment) and 20 (sunlight and UV experiments) true leaves were excised, sporangia of $B$. lactucae were collected by washing leaves with $5.5 \mathrm{ml}$ of sterile water in a glass tube, and the sporangium suspension was filtered through a cloth. After centrifugation $(8,900 \times g$ for $30 \mathrm{~s})$, sporangia were resuspended with $3.0 \mathrm{ml}$ of sterile water, and the process was repeated three times. The last time only $0.5 \mathrm{ml}$ of sterile water was used to resuspend sporangia, and the suspension was incubated at 13 to $15^{\circ} \mathrm{C}$ in the dark for $24 \mathrm{~h}$. At least 200 sporangia were examined under a microscope to determine the percent germinated. A sporangium was considered germinated if the germ tube was equal to or longer than the length of the sporangium.

Seedlings with remaining leaves were sprayed with distilled water and covered in plastic boxes. These seedlings were incubated at $15^{\circ} \mathrm{C}$ in a $12 \mathrm{~h}$ dark and $12 \mathrm{~h}$ light cycle for 6 days. On day 7 , some water was sprayed on seedlings to promote sporulation of downy mildew. Downy mildew symptoms were evaluated after 2 days. A seedling was considered diseased only when downy mildew sporulation was visible.

Meteorological measurements. To estimate the effects of UV on the survival of B. lactucae in nature, we collected data on total SR, UV, and UVB in Salinas, CA. Total UV and SR were measured as described above on 23 days ranging from 9 July to 26 September 1997. In addition to total UV, UVB was estimated from observations taken on 5 days ranging from 26 June to 14 July 1998. UVB was estimated from the measurements of a total UV radiometer with special filters (Models WG305, BG26, BG40, and UG5; Coherent Auburn Group, Auburn, CA).

Data analysis. The percentage of germinated sporangia $\left(G_{t}\right)$ after exposure for time $(t)$ was divided by the percentage of germination before exposure $\left(G_{0}\right)$ to obtain the relative germination percentage $\left(R G_{t}\right)$, because not all of the sporangia germinated in the control treatment. Repeated measures analysis of variance was carried out on $R G_{t}$ for all of the exposure experiments. $R G_{t}$ data of sporangia exposed to different temperature- $\mathrm{RH}$ combinations (three replications) were fitted to an exponential decay model:

$$
R G_{t}=\left[\alpha+(1-\alpha) e^{-\gamma t}\right] \times 100 \%
$$

where $\alpha$ and $\gamma$ are asymptote and slope of the fitted curve, respectively, estimated by nonlinear regression. The estimated parameter values and their standard errors were tested for differences between temperature and RH levels by Student's $t$ test.

Nonlinear regression analyses with an exponential decay model were also conducted on $R G_{t}$ after exposure to artificial light with different wavelength ranges, and $t$ tests compared the dark control with each of the other treatments.

Data obtained from experiments on the effects of exposure to SR on survival of sporangia were fitted to an exponential decay model. Curve fitting was done for each treatment and replication combination. Both $F$ tests and Duncan's multiple range tests were carried out on the parameters. In addition, a model was fitted for dose effects of total UV measured in the SR exposure experiments. First, an exponential model was fitted to the decline of relative germination percent exposed to the darkness treatment:

$$
R G D_{t}=\left[\alpha_{0}+\left(1-\alpha_{0}\right) e^{-\gamma t}\right] \times 100 \%
$$

Then, the predicted germination under darkness at time $t\left(R G D_{t}\right)$ was used as a control to standardize the germination after exposure to solar radiation $\left(R G_{t}\right)$ :

$$
S R G_{t}=\left(R G_{t}-R G D_{t}\right) / R G D_{t}
$$

Standardized relative germination $\left(S R G_{t}\right)$ versus the cumulative dose $(d)$ of total UV was fitted to a different exponential model with a maximum of 0 :

$$
S R G_{t}=\theta-\theta e^{-\beta d}
$$

The two models then were combined to obtain a model to predict relative germination $\left(R G_{t}\right)$ from exposure time $(t)$ and total UV dose $(d)$ :

$$
\begin{gathered}
R G_{t}^{\prime}=R G D_{t}+R G D_{t} \times S R G_{t}= \\
\left\{\alpha_{0}+\left(1-\alpha_{0}\right) e^{-\gamma t}+\left[\alpha_{0}+\left(1-\alpha_{0}\right) e^{-\gamma t}\right]\left(\theta-\theta e^{-\beta d}\right)\right\} \times 100 \%
\end{gathered}
$$

We compared the predictions of the last model (equation 5) with the observations by plotting predicted relative germination against observed relative germination.

\section{RESULTS}

Viability of sporangia after temperature-RH treatment combinations. Germination of sporangia decreased significantly as the exposure time increased for various treatments (Fig. 2 and Table 1). For each RH, the higher the temperature, the more rapid was the decline in germination. The effect of temperature on viability of sporangia was highly significant, but the effect of RH was not. Interaction effects of temperature-time and temperatureRH were also significant. Temperature effects were most signifi- 
cant $2 \mathrm{~h}$ after exposure. Differences in nonlinear regression parameters between RH treatments were not significant for all temperatures (data not shown). Therefore, all germination data for the four RH treatments under the same temperature were combined, and only one model was fitted for each temperature. The curve for $31^{\circ} \mathrm{C}$ had a significantly higher decline rate (slope) and a lower asymptote than for $23^{\circ} \mathrm{C}$ (Fig. 3). The infection of inoculated plants (data not shown) followed trends similar to germination, and the same was also true for the following experiments.

Germination of sporangia exposed to SR. Effects of treatment, time, and their interactions on germination were significant (Table 2). Relative germination percent declined more rapidly (steeper slope) for sporangia exposed to 50 and $100 \%$ SR than for those that remained in darkness (Table 3). There were no significant differences in the fitted asymptotes among different treatments, none of them were significantly different from 0 .

TABLE 1. Results of repeated measures analysis of variance of relative germination percentage of Bremia lactucae sporangia exposed to different temperature $(\mathrm{T}) \times$ relative humidity $(\mathrm{RH})$ treatments

\begin{tabular}{lccc}
\hline Source & df & Type III SS & $P r>F$ \\
\hline $\mathrm{T}$ & 1 & 1.303 & 0.009 \\
Error & 4 & 0.224 & \\
$\mathrm{RH}$ & 3 & 0.021 & 0.067 \\
$\mathrm{RH} \times \mathrm{T}$ & 3 & 0.031 & 0.026 \\
Error & 9 & 0.019 & \\
Time & & & \\
Time $\times \mathrm{T}$ & 5 & 1.018 & 0.001 \\
Error & 5 & 0.397 & 0.002 \\
& 20 & 0.274 & \\
Time $\times \mathrm{RH}$ & & & \\
Time $\times \mathrm{T} \times \mathrm{RH}$ & 15 & 0.075 & 0.232 \\
Error & 15 & 0.096 & 0.086 \\
\hline
\end{tabular}

${ }^{\mathrm{z}} \mathrm{SS}=$ sum of squares.
The decline in relative germination of $B$. lactucae sporangia remaining in darkness was described adequately by an exponential decay model (Fig. 4). The coefficient of determination for the model was 0.97 . The standardized relative germination of $B$. lactucae sporangia exposed to SR decreased from 0 to $\approx-1.0$ as the cumulative UV dose increased from 0 to $\approx 0.9 \mathrm{MJ} \mathrm{m}^{-2}$ (Fig. 5). The relationship between total UV dose and standardized relative germination was also described by an exponential decay model. After combining the two parts (Figs. 4 and 5) together, the following model

$$
\begin{aligned}
R G_{t}^{\prime} & =0.0392+0.9608 e^{-0.2635 t}+\left(0.0392+0.9608 e^{-0.2635 t}\right) \times \\
& \left(-0.9976+0.9976 e^{-4.3962 d}\right)=0.002306 e^{-0.2635 t} \\
& +0.03911 e^{-4.3962 d}+0.9585 e^{-0.2635 t-4.3962 d}
\end{aligned}
$$

could be used to estimate relative germination of B. lactucae sporangia exposed to SR based on exposure time $(t)$ and total UV dose $(d)$. The relationship between fitted and observed relative germination did not deviate significantly from the theoretical line (Fig. 6).

Germination of sporangia exposed to lights with different wavelength ranges. In all the treatments, relative germination of B. lactucae declined as exposure time increased, but it declined more rapidly for sporangia exposed to UVB than for those exposed to any other type of light or dark treatment. Repeated measures analysis of variance showed significant effects of treatment, time, and their interactions (Table 4). Significant differences in relative germination between sporangia exposed to UVB and those that remained in the dark were observed for all the sampling times (Table 5). Percentage of sporangium germination between dark and fluorescent light treatments was not significantly different for any of the sampling times. For UVA, only sporangia exposed to the high level of UVA for $8 \mathrm{~h}$ showed reduced germination, compared with sporangia that remained in the dark.

Measurements of SR, total UV, and UVB. In the Salinas area, total SR and UV reached their daily peaks around $1215 \mathrm{~h}$ during the observation periods (Fig. 7). The ratio of total UV to SR var-

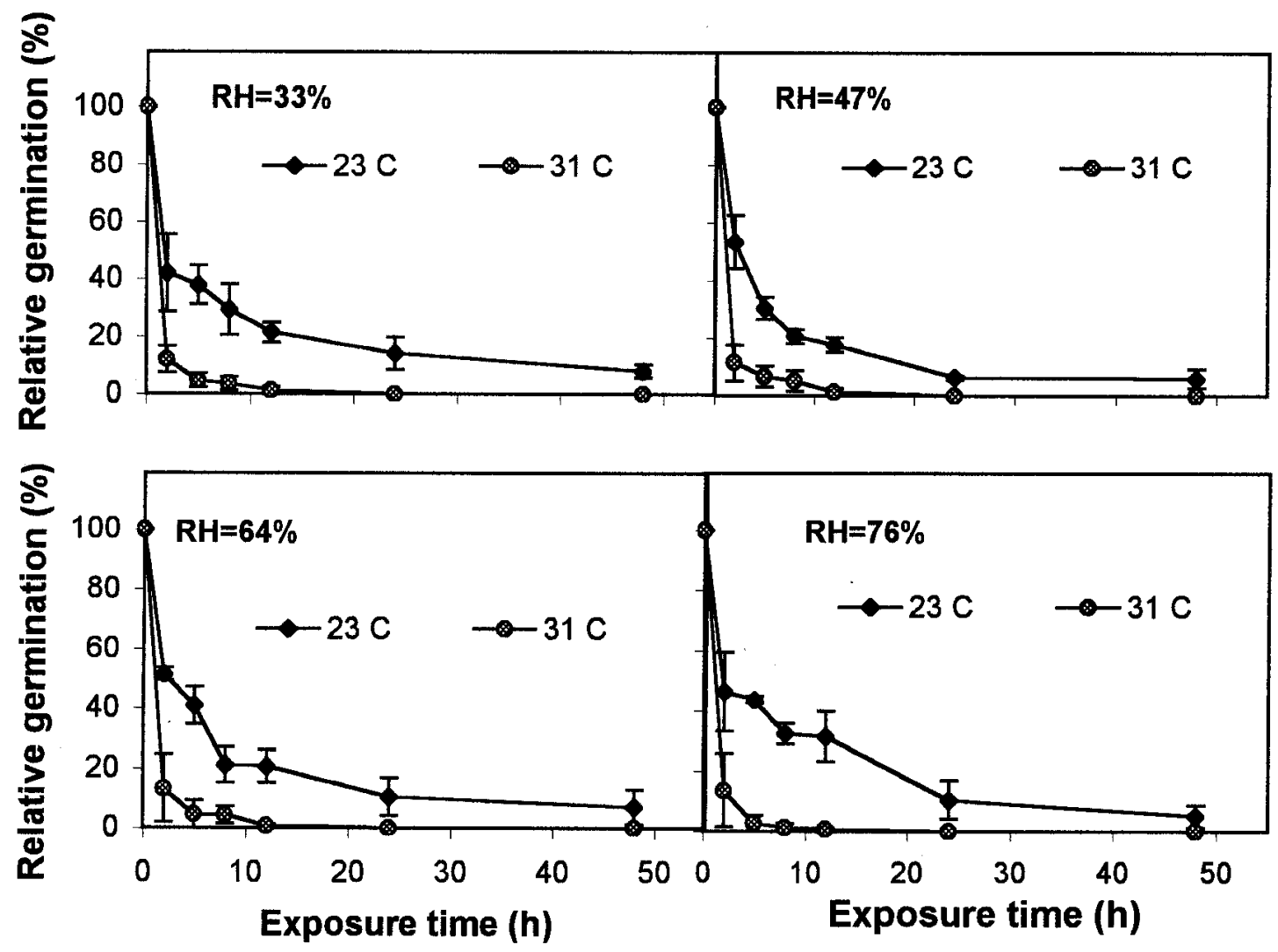

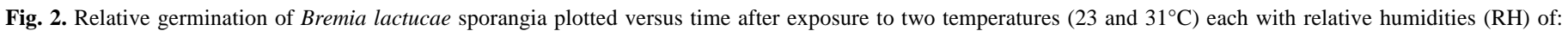
A, 33\%; B, 47\%; C, 64\%; D, 76\%. 
ied between 0.040 and 0.045 during 0800 to $1600 \mathrm{~h}$ and reached its daily peak around the same time as total SR and UV (Fig. 7). UVB followed a similar daily trend during observation days (Fig. $8 \mathrm{~A}$ and $\mathrm{B}$ ), but the variations of UVB among days were greater than those of total UV, which showed great variation only between cloudy and clear days (1 July was cloudy and the other days were clear). The ratio of UVB to total UV increased slightly from 0900 to $1400 \mathrm{~h}$ and reached a plateau subsequently (Fig. 8C). Its multiple day trends showed a sustained increase in the ratio from 26 June to 14 July 1998 (Fig. 8C).

\section{DISCUSSION}

This study demonstrates that B. lactucae sporangia deposited on lettuce leaves may survive for fairly long periods at more or less adverse temperatures and RH levels. B. lactucae sporangia survived better at lower temperatures than at higher temperatures but showed no significant differences in survival under different $\mathrm{RH}$ treatments. This result is consistent with the results obtained previously for other oomycetes $(3,17,21,30)$. Sporangia of closely related oomycetes $(3,17)$ survived better at cool temperatures and moderate RH after being detached and survived only for a short period at low RH and high temperature when an artificial surface was used in survival tests. Experiments have also shown that the viability of $B$. lactucae sporangia is longest at lower temperatures and at a relatively low humidity (20). When sporangia were deposited on leaves they were very resistant to desiccation, especially at $2^{\circ} \mathrm{C}(30)$. Wallin (31) and Rotem and Cohen (21) found that $P$. infestans could remain viable for longer periods, either

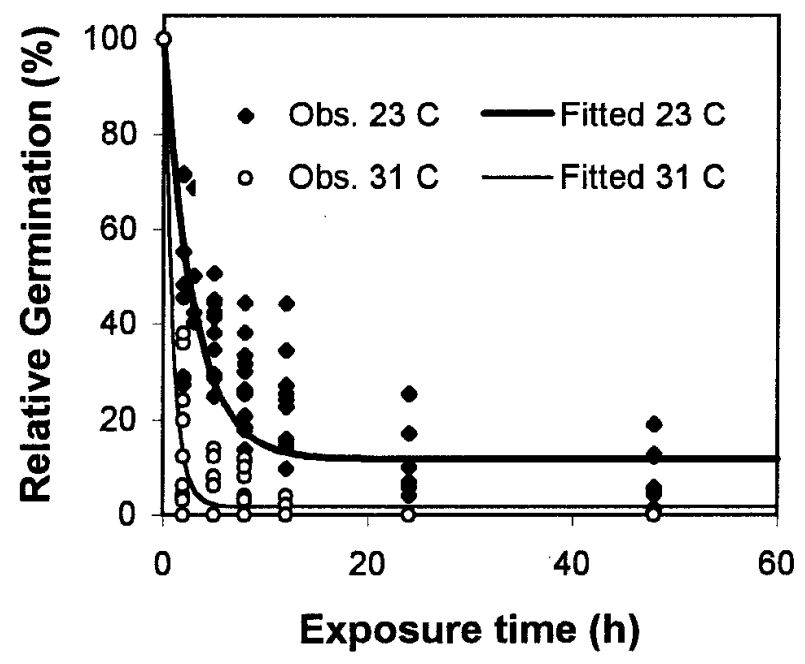

Fig. 3. Observed relative germination $(R G)$ and fitted relative germination percentage $\left(\mathrm{RG}_{t}{ }^{\prime}\right)$ of Bremia lactucae sporangia after exposure to different temperatures. Models fitted by nonlinear regression analysis were $R G_{t}{ }^{\prime}=0.1359$ $( \pm 0.0208)+(1-0.1359) e^{-0.2901( \pm 0.0268) t}$, and $R G_{t}^{\prime}=0.0173( \pm 0.0077)+(1-$ $0.0 .0173) e^{-1.0865( \pm 0.0819) t}$, for 23 and $31^{\circ} \mathrm{C}$, respectively.

TABLE 2. Results of repeated measures analysis of variance of relative germination percentage of Bremia lactucae sporangia exposed to four levels of sunlight

\begin{tabular}{lcccc}
\hline Source & df & Type III SS & $F$ & $\operatorname{Pr}>F$ \\
\hline Treatment & 3 & 0.567 & 67.77 & 0.0001 \\
Replication & $3^{\mathrm{z}}$ & 0.127 & 15.14 & 0.0007 \\
Error & 9 & 0.025 & & \\
& & & & \\
Time & 4 & 2.148 & 256.84 & 0.0001 \\
Time $\times$ treatment & 12 & 0.102 & 4.08 & 0.0005 \\
Time $\times$ replication & 12 & 0.111 & 4.43 & 0.0002 \\
Error & 36 & 0.075 & & \\
\hline
\end{tabular}

y $\mathrm{SS}=$ sum of squares.

$\mathrm{z}$ The germination data at $10 \mathrm{~h}$ were missing in two replications. before detachment (31) or after deposition on a leaf surface compared with after deposition on an artificial surface (21). Harrison (13) explained that transpiration of plant leaves ensured that the air surrounding the sporangia on a leaf surface was close to saturation and sporangia did not become desiccated even when ambient air was dry. It is not difficult to understand why we did not observe significant differences in the survival of B. lactucae sporangia among different $\mathrm{RH}$ treatments when the actual $\mathrm{RH}$ of the air surrounding the sporangia was almost the same in the different $\mathrm{RH}$ treatments because of the boundary layer near the leaf surface.

The epidemiological significance of these observations in coastal California is that the effects of $\mathrm{RH}$ in air on survival of deposited sporangia can be likely ignored in commercial fields. Temperature plays a minor role because the daily maximum temperature in

TABLE 3. Slopes ( $\gamma$ expressed in hours $\left.{ }^{-1}\right)$ and asymptotes $(\alpha)$ of the exponential decay model $\left(R G_{t}=\left[\alpha+(1-\alpha) e^{-\gamma t}\right] \times 100 \%\right)^{\mathrm{x}}$ estimated by nonlinear regression analyses of germination of Bremia lactucae sporangia exposed to various levels of solar radiation $(\mathrm{SR})^{\mathrm{y}}$

\begin{tabular}{lll}
\hline Treatment & Mean of $\gamma^{z}$ & Mean of $\alpha^{z}$ \\
\hline $100 \% \mathrm{SR}$ & $0.8614 \mathrm{~A}$ & $0.01415 \mathrm{~A}$ \\
$50 \% \mathrm{SR}$ & $0.6630 \mathrm{AB}$ & $0.01815 \mathrm{~A}$ \\
$25 \% \mathrm{SR}$ & $0.4519 \mathrm{BC}$ & $0.02208 \mathrm{~A}$ \\
Darkness & $0.3083 \mathrm{C}$ & $0.03278 \mathrm{~A}$ \\
\hline
\end{tabular}

$\mathrm{x}$ Model described in text.

y Six replications per treatment.

${ }^{\mathrm{z}}$ Means followed by the same letters are not significantly different according to Duncan's multiple range tests $(P \leq 0.05)$.

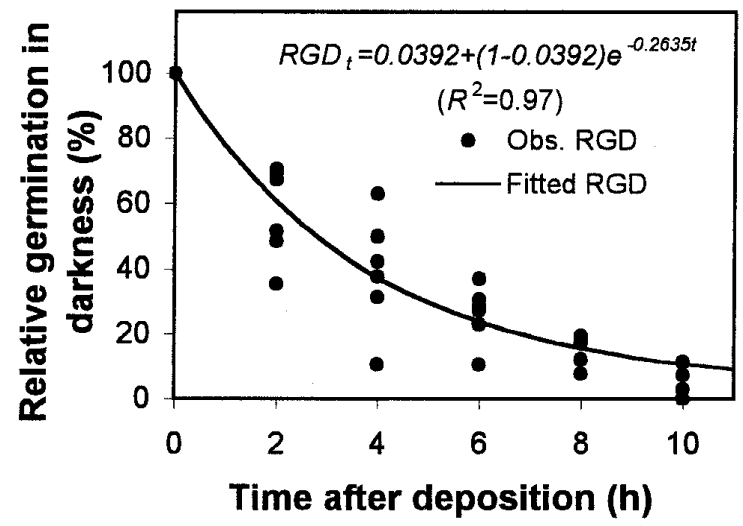

Fig. 4. Relative germination percentage of Bremia lactucae sporangia placed in darkness over time, as described by an exponential decay model.

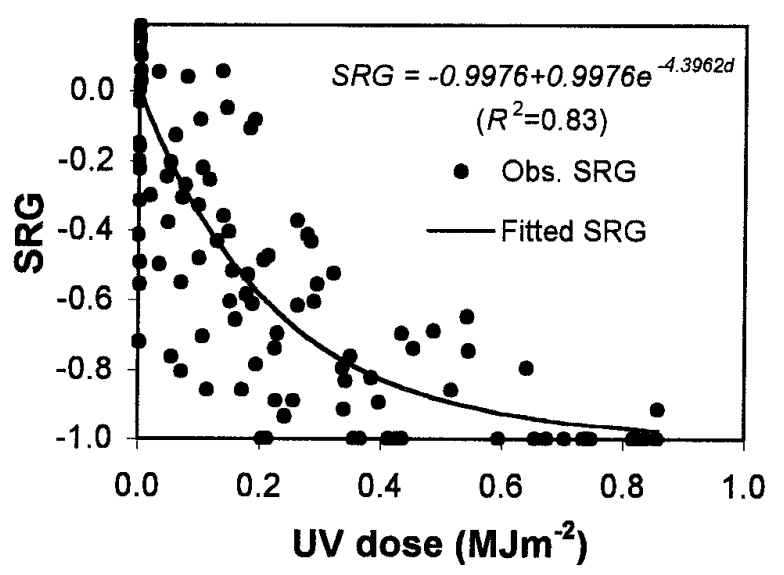

Fig. 5. Standardized relative germination $(S R G)$ of Bremia lactucae sporangia after exposure to natural solar radiation plotted against the UV dose received by sporangia deposited on lettuce leaves. 
these lettuce production areas is relatively moderate and many sporangia can survive more than $8 \mathrm{~h}$ at $31^{\circ} \mathrm{C}$. If there are any important effects of temperature and $\mathrm{RH}$ on survival of $B$. lactucae in lettuce fields, the effects are most likely to occur during longdistance transport of sporangia when they are more susceptible to adverse environmental conditions. Therefore, temperature and $\mathrm{RH}$ are likely to have smaller effects during secondary spread than during the establishment of new foci through long-range dispersal.

In our study, the viability of B. lactucae decreased rapidly when exposed to SR, approaching an asymptote when the total UV dose increased to $\approx 0.5 \mathrm{MJ} \mathrm{m}^{-2}$. This UV dose was less than one-half of the total UV dose reaching the earth's surface on a summer day in

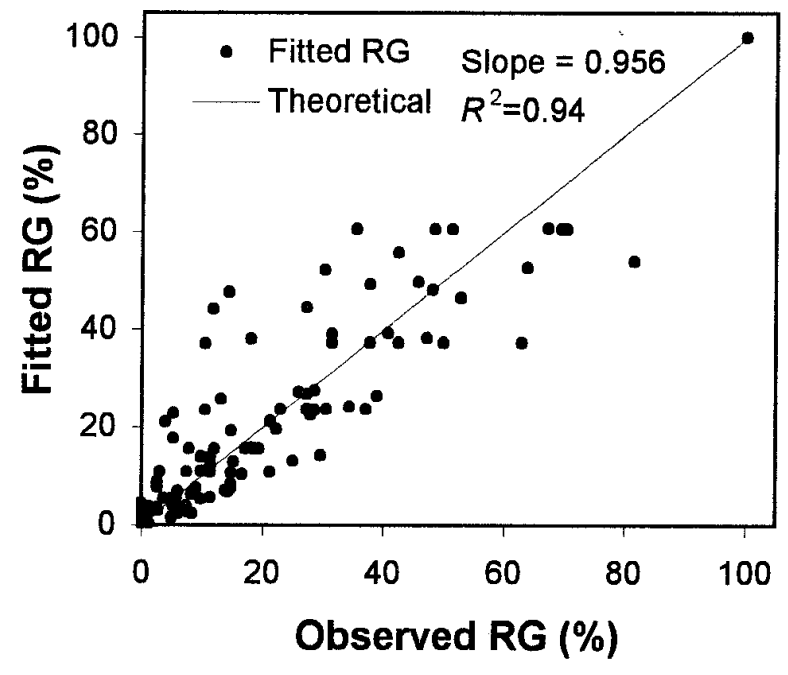

Fig. 6. Comparison of estimated relative germination percentage (fitted $R G$ ) by the model with observed relative germination percentage (observed $R G$ ) of Bremia lactucae sporangia exposed to solar radiation.

TABLE 4. Results of repeated measures analysis of variance of relative germination percentage of Bremia lactucae sporangia exposed to different wavelengths of light

\begin{tabular}{lrcrc}
\hline Source & df & Type III SS & $F$ & $\operatorname{Pr}>F$ \\
\hline Treatment & 5 & 1.637 & 14.22 & 0.0002 \\
Replication & 1 & 0.108 & 4.68 & 0.0534 \\
Error & 11 & 0.253 & & \\
& & & & \\
Time & 4 & 1.429 & 49.67 & 0.0001 \\
Time $\times$ treatment & 20 & 0.619 & 4.30 & 0.0001 \\
Time $\times$ replication & 4 & 0.121 & 4.22 & 0.0056 \\
Error & 44 & 0.316 & & \\
\hline
\end{tabular}

${ }^{\mathrm{z}} \mathrm{SS}=$ sum of squares

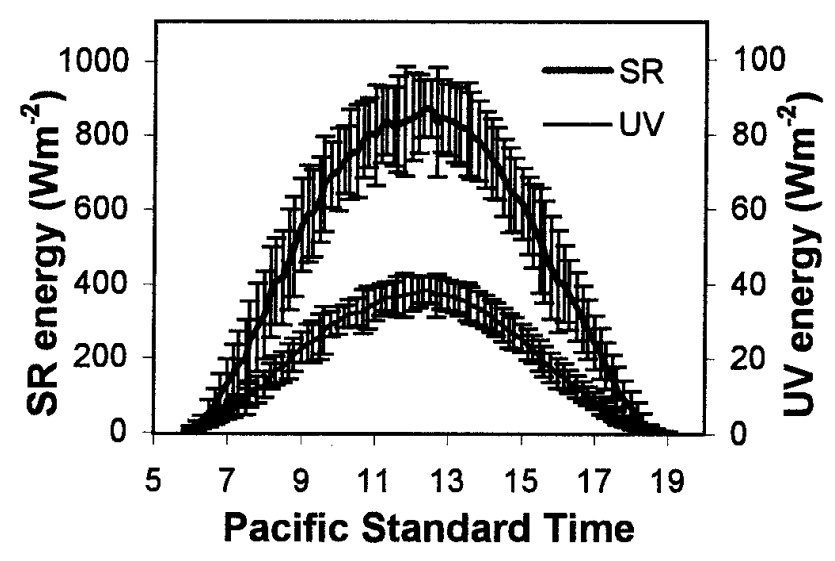

Fig. 7. Total solar radiation (SR) and total UV from 0700 to $1900 \mathrm{~h}$ measured in Salinas, CA, during summer 1997. coastal California. This result is very similar to the results obtained for Peronospora tabacina and Peronospora destructor (23). Attached sporangia of Peronospora tabacina survived significantly better than detached ones, but both attached and detached sporangia of Peronospora tabacina were sensitive to sunlight and short wavelength UV (23). The germination percentage of de-

TABLE 5. Mean relative germination percentage of Bremia lactucae sporangia after exposure to different wavelengths of light for different time periods

\begin{tabular}{lcccc}
\hline Treatment $^{\mathrm{z}}$ & $2 \mathrm{~h}$ & $4 \mathrm{~h}$ & $8 \mathrm{~h}$ & $12 \mathrm{~h}$ \\
\hline Dark & $56.6 \mathrm{~A}$ & $64.0 \mathrm{~A}$ & $38.6 \mathrm{~A}$ & $31.6 \mathrm{~A}$ \\
FL & $48.5 \mathrm{~A}$ & $49.8 \mathrm{~A}$ & $37.7 \mathrm{~A}$ & $28.3 \mathrm{~A}$ \\
UVA1 & $46.4 \mathrm{~A}$ & $46.9 \mathrm{~A}$ & $33.6 \mathrm{~A}$ & $22.0 \mathrm{~A}$ \\
UVA2 & $42.8 \mathrm{~A}$ & $38.1 \mathrm{AB}$ & $20.8 \mathrm{~B}$ & $16.6 \mathrm{~A}$ \\
UVB1 & $13.9 \mathrm{~B}$ & $9.4 \mathrm{BC}$ & $4.8 \mathrm{C}$ & $1.3 \mathrm{~B}$ \\
UVB2 & $4.6 \mathrm{~B}$ & $1.3 \mathrm{C}$ & $0.4 \mathrm{C}$ & $0.0 \mathrm{~B}$ \\
\hline
\end{tabular}

${ }^{\mathrm{z}} \mathrm{FL}=$ Florescent light $\left(4.0 \mathrm{~W} \mathrm{~m}^{-2}\right)$; UVA1 $=$ ultraviolet $\mathrm{A}\left(6.0 \mathrm{~W} \mathrm{~m}^{-2}\right)$ peak at 340 to $350 \mathrm{~nm}$; UVA2 = ultraviolet $\mathrm{A}\left(12.5 \mathrm{~W} \mathrm{~m}^{-2}\right)$ peak at 340 to $350 \mathrm{~nm}$; $\mathrm{UVB} 1=$ ultraviolet $\mathrm{B}\left(1.5 \mathrm{~W} \mathrm{~m}^{-2}\right)$ peak at 305 to $310 \mathrm{~nm}$; UVB2 $=$ ultraviolet $\mathrm{B}$ $\left(7.0 \mathrm{~W} \mathrm{~m}^{-2}\right)$ peak at 305 to $310 \mathrm{~nm}$. Means within the same column followed by same letter are not significantly $(P=0.05)$ different according to Duncan's multiple range tests
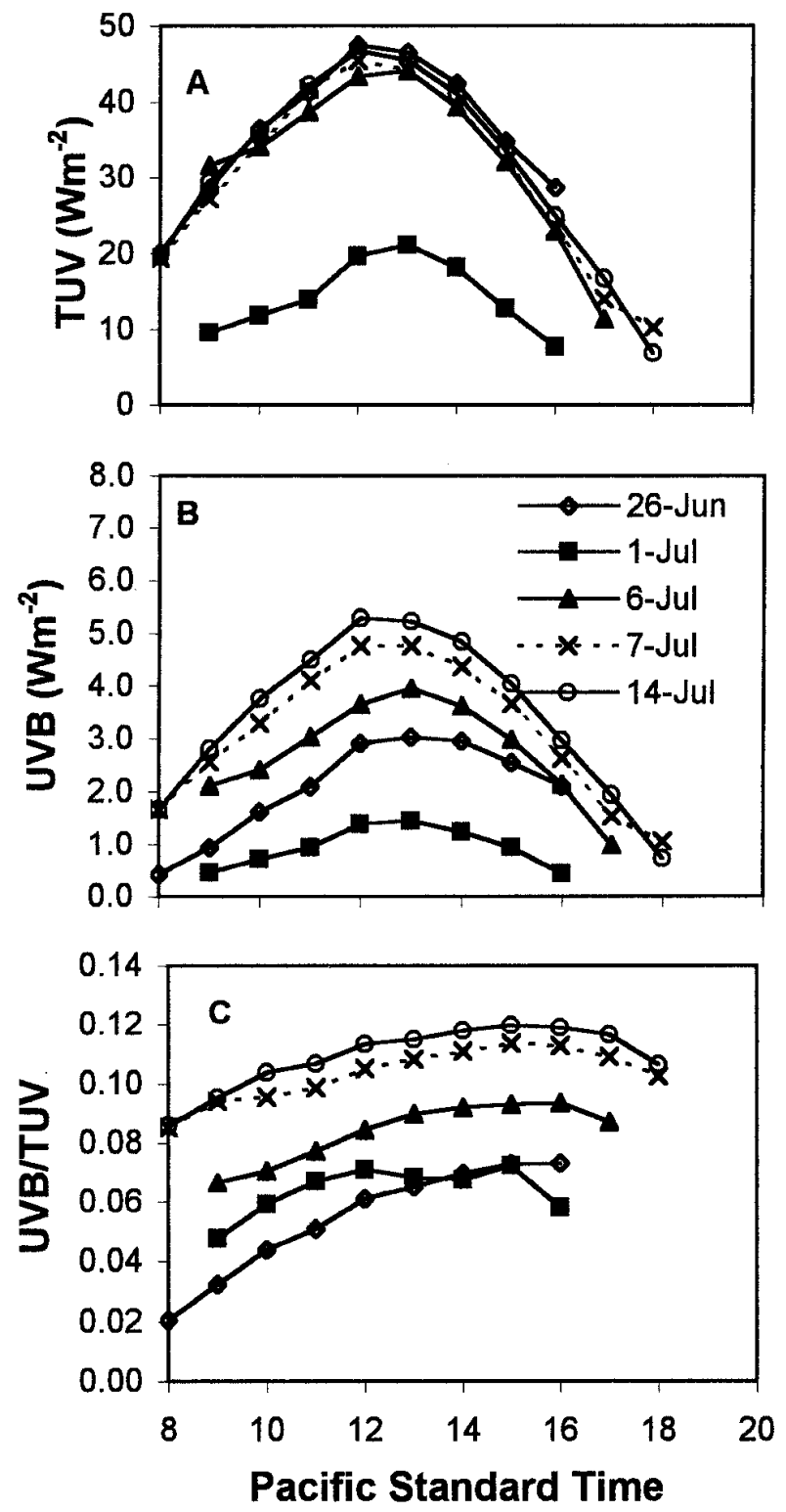

Fig. 8. A, Total UV (TUV); B, UVB and; C, ratio of UVB to TUV measured from 0800 to $1800 \mathrm{~h}$ in Salinas, CA, during summer 1998. 
tached Peronospora tabacina sporangia decreased greatly from $100 \%$ to less than $5 \%$ when the total UV dose in a sunlight exposure experiment reached $0.5 \mathrm{MJ} \mathrm{m}^{-2}$. Bashi and Aylor (3) found that germination of Peronospora destructor sporangia decreased to almost zero after exposure to direct SR of 700 to $900 \mathrm{~W} \mathrm{~m}^{-2}$ for $\approx 3 \mathrm{~h}$. Assuming that the percentage of the UV component in sunlight was $5 \%$, the same as in a previous experiment (1), the total $\mathrm{UV}$ dose for this period would have been $\approx 0.45 \mathrm{MJ} \mathrm{m}^{-2}$. However, $V$. inaequalis conidia were more resistant to the UV in natural sunlight and their germination percent reached an asymptote after receiving more than $1.0 \mathrm{MJ} \mathrm{m}^{-2}$ of total UV dose (1). Uromyces phaseoli and Alternaria solani were even more resistant, and their germination percent decreased to $\approx 0$ only after a total UV dose of $2 \mathrm{MJ} \mathrm{m}^{-2}$ (23). Therefore, the sensitivity of spores to UV may depend on the type of spore pigmentation and reflect the genetic relatedness of plant pathogens; the hyaline sporangium of $B$. lactucae were among the most sensitive plant pathogens.

In our experiments with lights in different wavelength ranges (UVA and UVB), only UVB played a role in killing sporangia of $B$. lactucae. Moreover, the required UVB dose was lower when sporangia were exposed to UVB light in the laboratory than when they were exposed to natural sunlight. It is known that responses of plants to UVB depend on how much UVB they receive and also on the environmental conditions under which the plants are irradiated. Results of a previous field study (5) indicated that UVA had mitigating effects on UVB reduction of plant growth. This may explain why the dose effect of UVB is larger when only UVB is used than when total SR (including UVA and UVB) is used.

In this study, we measured total UV and UVB with a total UV radiometer with various filters. It was hoped that the level of UVB, the most important wavelength for assessment of potential biodamage, can be predicted from total SR level and used for prediction of this disease, because total SR is the only measurement documented by most weather stations in coastal California. Similar to total SR, the daily patterns and peaks of total UV remained almost the same during the research period, except that the peaks were affected by cloud cover. However, the level of UVB varied widely even on clear days. This might have resulted from the variation in the ozone layer, which affects mainly short UV components of SR. The daily pattern of the UVB and UV ratio also differed from that of total UV to total SR. Therefore, it may be difficult to predict UVB dose directly from SR.

On most clear days, the total UV dose was $\approx 0.95 \mathrm{MJ} \mathrm{m}^{-2}$ (calculated from Figs. 7 and 8A), much higher than $0.5 \mathrm{MJ} \mathrm{m}^{-2}$, the dose that was required to kill most of the B. lactucae sporangia. The UVB dose was also higher than the level of UVB1 we used in the experiment, showing significant deleterious effects of UVB on the viability of sporangia within $4 \mathrm{~h}$. Although we took measurements only on a few days and used a total UV radiometer with filters instead of a precise UVB sensor, the results indicate that the UVB and total UV dose in the main lettuce production area in coastal California was high enough to kill B. lactucae sporangia, except on very cloudy days. In addition to clouds, shading by leaves may be another factor increasing sporangium survival. In exposure experiments, although there was probably variability in the sensitivity to radiation in the sporangium population, some sporangia could have survived because they were deposited on bottom leaves and shaded by upper leaves. This may explain why downy mildew is usually observed on the bottom leaves in fields, because they are shaded by the upper leaves later in the season.

\section{LITERATURE CITED}

1. Aylor, D. E., and Sanogo, S. 1997. Germinability of Venturia inaequalis conidia exposed to sunlight. Phytopathology 87:628-633.

2. Aylor, D. E., Taylor, G. S., and Raynor, G. S. 1982. Long-range transport of tobacco blue mold spores. Agric. Meteorol. 27:217-232.

3. Bashi, E., and Aylor, D. E. 1983. Survival of detached sporangia of Peronospora destructor and P. tabacina. Phytopathology 73:1135-1139.
4. Bashi, E., Ben Joseph, Y., and Rotem, J. 1982. Inoculum potential of Phytophthora infestans and the development of potato late blight epidemics. Phytopathology 72:1043-1047.

5. Caldwell, M. M., Flint, S. D., and Searles, P. S. 1994. Spectral balance and UV-B sensitivity of soybean: A field experiment. Plant Cell Environ. 17:267-276.

6. Coohill, T. P. 1989. Ultraviolet action spectra (280-380 nm) and solar effectiveness spectra for higher plants. Photochem. Photobiol. 50:451-457.

7. Crosier, W. 1934. Studies in the biology of Phytophthora infestans (Mont.) de Bary. Cornell Univ. Agric. Exp. Stn. Membr. 115.

8. Cullen, J. J., Neale, P. J., and Lesser, M. P. 1992. Biological weighting function for the inhibition of phytoplankton photosynthesis by ultraviolet radiation. Science 258:646-650.

9. De Weille, G. A. 1964. Forecasting crop infection by the potato blight fungus. Meded. Verh. K. Ned. Met. Inst. 82:1-144.

10. Diffey, B. L. 1991. Solar ultraviolet radiation effects on biological systems. Phys. Med. Biol. 36:299-328.

11. Fletcher, J. 1976. Bremia lactucae, oospores, sporangial dissemination, and control. Ann. Appl. Biol. 84:294-298.

12. Gunasekera, T. S., Paul, N. D., and Ayres, P. G. 1997. The effects of ultraviolet-B (UV-B: 290-320 nm) radiation on blister blight disease of tea (Camellia sinensis). Plant Pathol. 46:179-185.

13. Harrison, J. G. 1992. Effects of the aerial environment on late blight of potato foliage: A review. Plant Pathol. 41:384-416.

14. Hildebrand, P. D., and Sutton, J. C. 1984. Effects of weather variables on survival and infection of onion leaves by Peronospora destructor. Can. J. Plant Pathol. 6:119-126.

15. Hoagland, D. R., and Arnon, D. I. 1950. The water culture method for growing plants without soil. Calif. Agric. Exp. Stn. Circ. 347:1-23.

16. Leung, H. 1994. Effects of ultraviolet-B irradiation on spore viability, sporulation, and mutation of the rice blast fungus. Pages 158-168 in: Climate Change and Rice. S. Peng, K. T. Ingram, H. U. Neue, and L. H. Ziska, eds. Springer-Verlag, New York.

17. Minogue, K. P., and Fry, W. E. 1981. Effects of temperature, relative humidity, and rehydration rate on germination of dried sporangia of Phytophthora infestans. Phytopathology 71:1181-1184.

18. Mizubuti, E. S. G., Aylor, D. E., and Fry, W. E. 2000. Survival of $P h$ ytophthora infestans sporangia exposed to solar radiation. Phytopathology 90:78-84.

19. Populer, C. 1981. Epidemiology of downy mildews. Pages 57-105 in: The Downy Mildews. D. M. Spencer, ed. Academic Press, New York.

20. Powlesland, R. 1954. On the biology of Bremia lactucae. Trans. Br. Mycol. Soc. 37:362-371.

21. Rotem, J., and Cohen, Y. 1974. Epidemiological patterns of Phytophthora infestans under semi-arid conditions. Phytopathology 64:711-714.

22. Rotem, J., Palti, J., and Lomas, J. 1970. Effects of sprinkler irrigation at various times of the day on development of potato late blight. Phytopathology 60:839-843.

23. Rotem, J., Wooding, B., and Aylor, D. E. 1985. The role of solar radiation, especially ultraviolet, in the mortality of fungal spores. Phytopathology 75:510-514.

24. Scherm, H., Koike, S. T., Laemmlen, F. F., and van Bruggen, A. H. C. 1995. Field evaluation of fungicide spray advisories against lettuce downy mildew (Bremia lactucae) based on measured or forecast morning leaf wetness. Plant Dis. 79:511-516.

25. Scherm, H., and van Bruggen, A. H. C. 1993. Response surface models for germination and infection of Bremia lactucae, the fungus causing downy mildew of lettuce. Ecol. Model. 65:281-296.

26. Scherm, H., and van Bruggen, A. H. C. 1994. Weather variables associated with infection of lettuce by downy mildew (Bremia lactucae) in coastal California. Phytopathology 84:860-865.

27. Scherm, H., and van Bruggen, A. H. C. 1995. Concurrent spore release and infection of lettuce by Bremia lactucae during mornings with prolonged leaf wetness. Phytopathology 85:552-555.

28. Su, H., van Bruggen, A. H. C., and Subbarao, K. V. 1998. Spore release of Bremia lactucae on lettuce is affected by timing of light initiation and decrease in relative humidity. Phytopathology 90:67-71.

29. Sutton, J. C., and Hildebrand, P. D. 1985. Environmental water in relation to Peronospora destructor and related pathogens. Can. J. Plant Pathol. 7:323-330.

30. Verhoeff, K. 1960. On the parasitism of Bremia lactucae Regel on lettuce. Tijschr. Plantenziekten 66:133-203.

31. Wallin, J. R. 1953. The production and survival of Phytophthora infestans on tomato and potato plants. Phytopathology 43:505-508.

32. Willocquet, L., Colombet, D., Rougier, M., Fargues, J., and Clerjeau, M. 1996. Effects of radiation, especially ultraviolet B, on conidial germination and mycelial growth of grape powdery mildew. Eur. J. Plant Pathol. 102:441-449. 